\title{
MAGNETIC MINERAL EXPLORATION USING GROUND MAGNETIC SURVEY DATA OF TAJIMI AREA, LOKOJA
}

\author{
E. O. JOSHUA, G. O. LAYADE, V. B. AKINBOBOYE AND S. A. ADEYEMI
}

(Received 7 March 2017; Revision Accepted 26 May 2017)

\begin{abstract}
Ground magnetic survey is an essential geophysical method employed in locating subsurface magnetic materials for possible exploration. In geophysics, the anomalous magnetization might be associated with local mineralization that is potentially of commercial interest. Hence a ground magnetic survey was carried out at a site in Tajimi area of Lokoja, Kogi State, Nigeria. The study is aimed at locating the position of iron deposited minerals within the study area. The study area lies within Latitude $8^{0} 0292^{\prime} \mathrm{N}$ to $8^{0} 0625^{\prime} \mathrm{N}$ and Longitude $6^{0} 5833^{\prime} \mathrm{E}$ to $6^{0} 6167^{\prime} \mathrm{E}$ in the basement complex of Southern Nigeria. A total of fifteen magnetic transverse lines were established in an E-W direction in the study area covering $140 \mathrm{~m}$ by $75 \mathrm{~m}$. Data were taken and recorded using Proton Precession magnetometer; the data were presented in magnetic profiles, 2D contour map and 3D surface map which aided the qualitatively interpretation. The study area was characterized by completely varying magnetic anomaly amplitudes across the field. The field data were quantitatively interpreted and the results gave values for the total component measurements of the ground magnetic anomaly that varied between a minimum negative peak value of about $-23428.7 \mathrm{nT}$ and a maximum positive peak value of about 5840.9nT. The residual anomalies obtained were plotted against distance using Microsoft Excel and Analytic signal method was used to estimates the depth to the magnetic source body. The estimated depths of the magnetic source body/rocks from the Earth surface fall in the interval of $1.28 \mathrm{~m}$ to $13.57 \mathrm{~m}$, which indicates the magnetic source body suspected to be magnetic mineral, are near surface features. Hence a careful analysis of the magnetic anomaly maps can give vital information about the magnetic distribution and mineral potential of the study area at Tajimi.
\end{abstract}

\section{INTRODUCTION}

Geophysics can be defined as a science which applies physical and mathematical method to study the subsurface, in other words, geophysics is an aspect of Earth science which probes the subsurface and interprets the surface conditions from the physical and mathematical parameters acquired from other physical sciences. Depending on the aims and objectives of investigation, there are many geophysical methods of prospecting that are applicable to different situations. These methods include; Magnetic method, gravity method, electrical method, electromagnetic method, to mention but few (Kearey and Brooks, 1984).

The purpose of magnetic surveying is to identify and describe regions of the Earth's crust that have unusual (anomalous) magnetizations.

Magnetic surveying consists of:

(1) Measuring the terrestrial magnetic field at predetermined points

(2) Correcting the measurements for diurnal variations

Comparing the resultant value of the field with the expected value at each measurement station.

Calculating the estimated depths from the Earth surface to the magnetic sources.
Several minerals containing iron and nickel display the property of ferromagnetism. Rocks containing these minerals can have strong magnetization and as a result can produce significant local magnetic fields (Nwankwo et al., 2006). The magnetic method is a geophysical technique that measures variations in the magnetic field to determine the location of subsurface features. Magnetic methods are sensitive to the susceptibility within the subsurface geology and so are ideal for exploring in the basement complex regions (Folami,1998).This non destructive technique has a numerous applications in engineering and environmental studies, including the location of voids, near surface fault, igneous dikes, and buried ferromagnetic objects like storage drums pipe (Weymouth, 1985). It's also used in mapping geological boundaries between magnetically contrasting lithologies including faults (Telford et al., 2001). Magnetic field variations can be interpreted to determine an anomaly's depth, geometry and magnetic susceptibility. Maps of magnetic anomalies are used to aid geological interpretations.

The theoretical undisturbed value of the magnetic field at any point on the Earth's surface is taken to be that of the International Geomagnetic Reference Field (IGRF). This formula is used to remove from the magnetic data those magnetic variations attributable to this theoretical field, leaving us with the residual magnetic anomaly data. Magnetic anomaly can

E. O. Joshua, Department of Physics, University of Ibadan, Nigeria.

G. O. Layade, Department of Physics, Federal University of Agriculture, Abeokuta, Nigeria.

V. B. Akinboboye, Department of Physics, University of Ibadan, Nigeria.

S. A. Adeyemi, Department of Physics, University of Ibadan, Nigeria. 
thus be defined as the difference between the measured magnetic field of the Earth and that which would be expected from the International Geomagnetic Reference Field (Lowrie, 2007). Although there is an alternative procedure suitable for small surveys, where the regional field is approximated by a linear trend and subsequently subtracted from the resultant field value for each measurement station. This procedure is refers to as Trend Analysis. (Kearey et al, 2002)

Other similar research works carried out in Nigeria using the magnetic survey method with the aid of proton precession magnetometer include; Determination of location and depth of mineral rocks at olode village in Ibadan (Akintayo et al., 2014), Ground magnetic survey for the investigation of mineral deposit at itesi village in orile ilugun Odeda (Joshua et al., 2013), Ground magnetic data interpretation of ljebuJesa area (Kayode and Adelusi, 2010) all in the southwestern part of Nigeria.

In this study, ground magnetic method was used in the search for iron deposited mineral materials. It aims at the locating position and approximate depth of burial of these ore minerals using the magnetic survey method.

\section{STUDY LOCATION AND GEOLOGY}

The study area is located on Latitude $8^{0} 0292$ ' $\mathrm{N}$ to $8^{0} 0625^{\prime} \mathrm{N}$ and Longitude $6^{0} 5833^{\prime} \mathrm{E}$ to $6^{0} 6167^{\prime} \mathrm{E}$ (Tajimi, Lokoja, Kogi State) with International geomagnetic reference field (IGRF) value of 333.8831 and lies within the basement complex of Southern Nigeria, which characterized by migmatite gneiss.(Elueze,1986, and Kayode, 2009).

The area fall under the banded iron formation of Nigeria, generally they occur in metamorphosed folded bands, associated with Precambrain basement complex rocks which included low meta-sediments, high grade schist, gneisses and migmatites. Included in this group are well known Lokoja-Okene occurrences notably at Itakpe, Ajabanoko, Chokochoko, Toto Muro and Taijimi in the Southwestern parts of Nigeria.

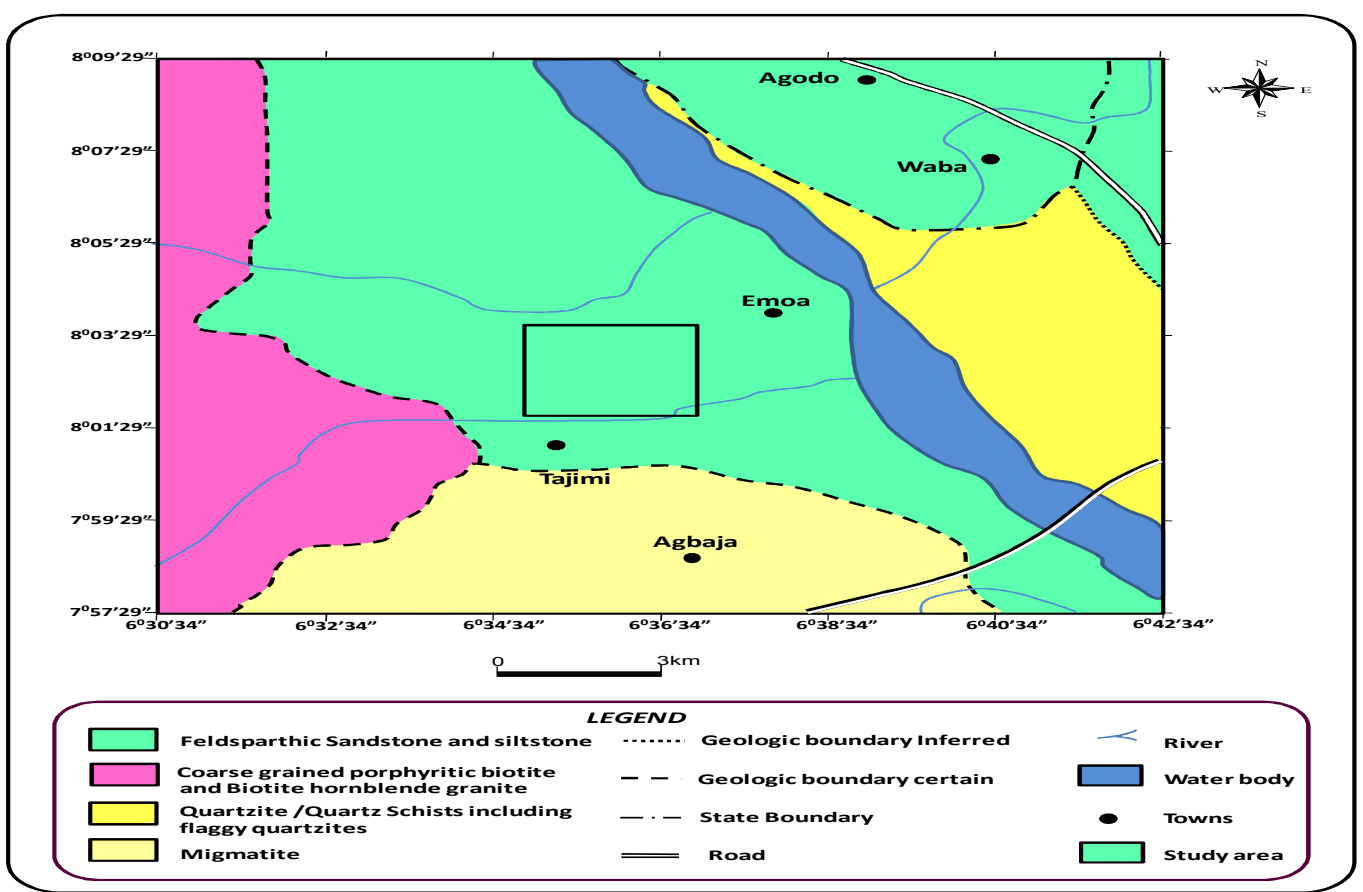

Fig 1.0: Geological map showing the study area (Adapted from Nigerian Geological Survey Agency, 2009)

\section{MATERIALS AND METHOD}

In this work, Magnetic measurements were carried out using the portable proton precession magnetometer (G$856 \mathrm{AX}$ ) over the sites at different-points covering $140 \mathrm{~m}$ by $75 \mathrm{~m}$. The Global Positioning System (GPS) was used to measure Longitude and Latitude along the profiles which were in turn used to generate the contour maps for the study area, with the aid of mapping software, Surfer10. The lines were oriented in an E-W direction, forming a rectangular area. A series of point at which the magnetic measurements were to be made were marked off along each profile line at $5 \mathrm{~m}$ interval between stations and $10 \mathrm{~m}$ interval between profile lines. The data collected were corrected using trend analysis to remove all contributions to the observed magnetic field other than those caused by sub-surface magnetic sources. The residual anomaly magnetic data were then plotted against distance to obtain magnetic field plots (figures2a-o) as well as against the Longitude and Latitude to obtain the 2D contour map and 3D surface distribution map of the whole survey area.

\section{DEPTH TO BASEMENT CALCULATION}

The analytic signal shape can be used to determine the depth to the magnetic sources. Atchuta Rao et al., (1981) and Roest et al., (1992) used the anomaly width at half the amplitude to derive the depths of magnetic sources from the Earth surface. Atchuta Rao et al., (1981) also used other characteristics of the analytic signal, which they refer to as complex gradient to help 
resolve the effect of overlapping edges (Macleod et al.,

1993). The following equations were used;

For a contact;

$x_{\frac{1}{2}}=2 \sqrt{3} h=3.46 h$

For a thin sheet (dyke);

$x_{\frac{1}{2}}=2 h$
For a horizontal cylinder;

$x_{\frac{1}{2}}=2(\sqrt[5]{4}-1)^{\frac{1}{2}} h=1.533 h$ ..iii

where $x_{\frac{1}{2}}$ is the width of the anomaly at half the amplitude from the magnetic plot graph and $h$ is the depth to the top of the contact.

\section{RESULT PRESENTATION AND DISCUSSION}

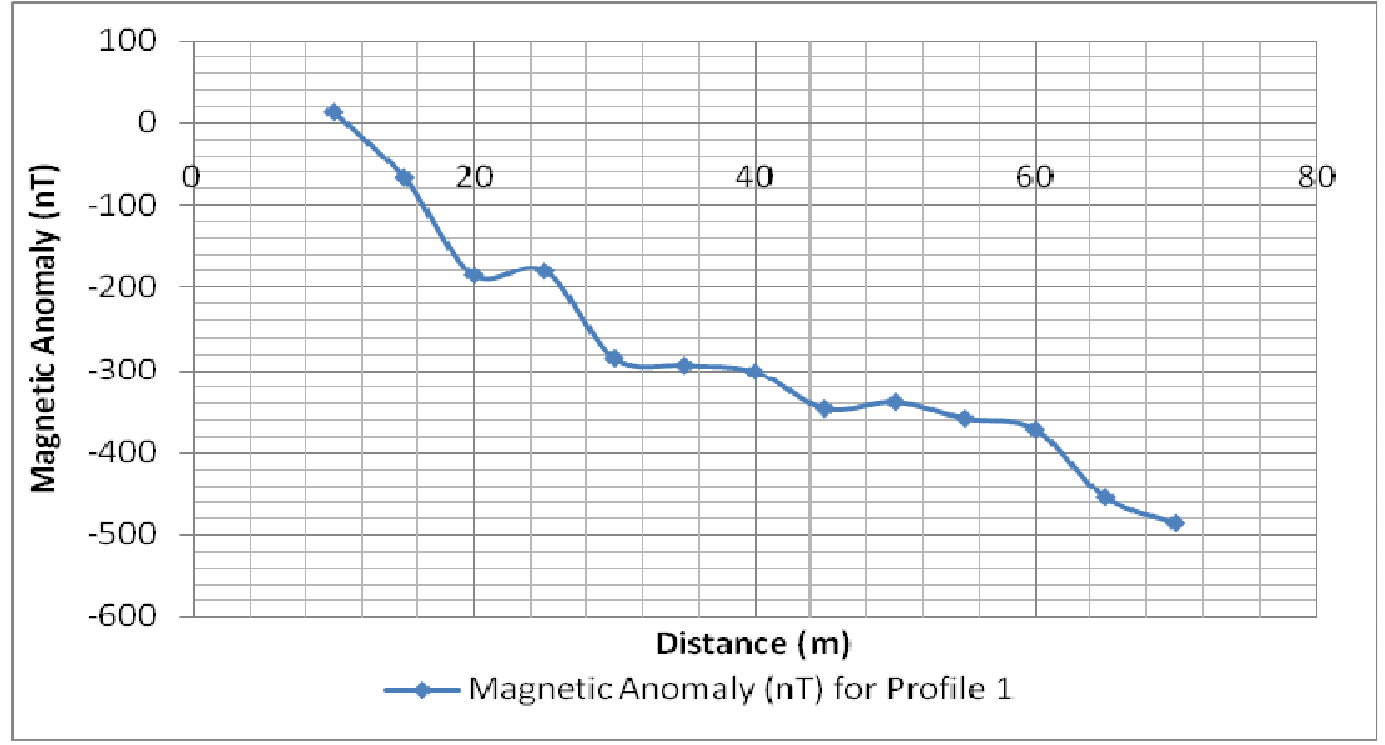

Figure 2a: Magnetic field plot for Profile 1

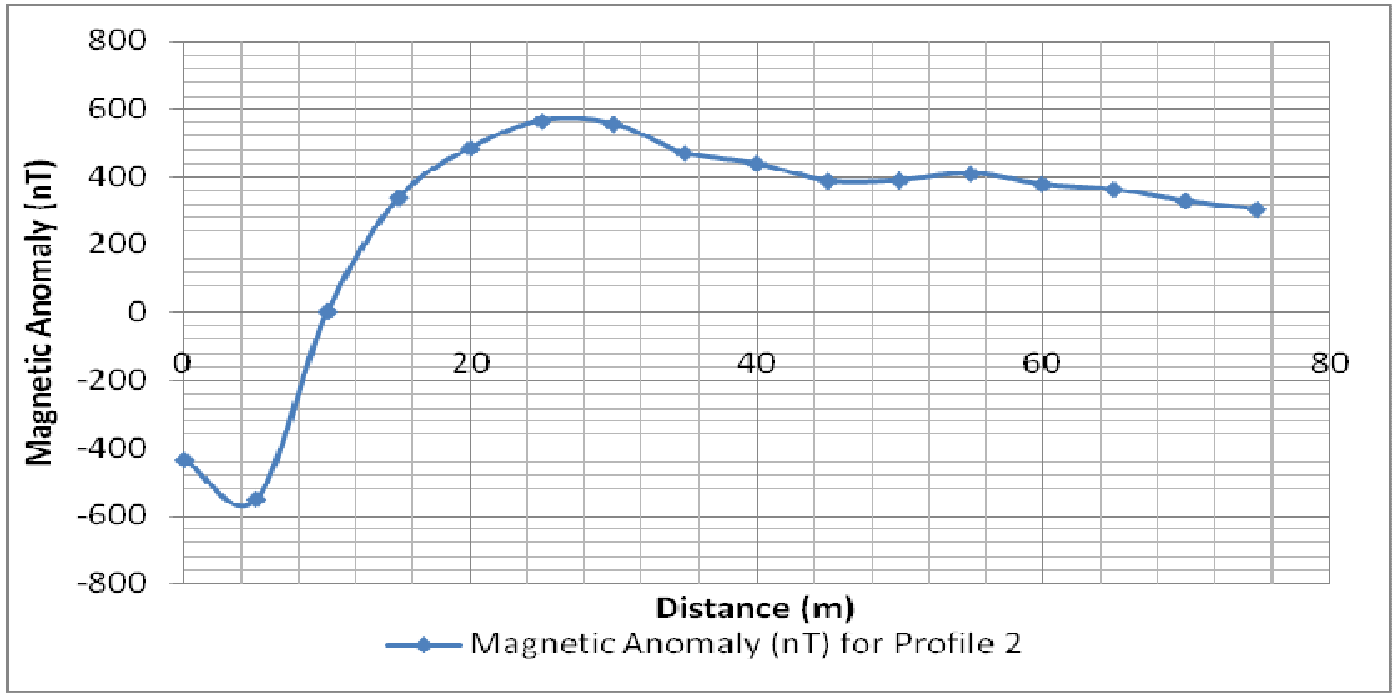

Figure 2b: Magnetic field plot for Profile 2 


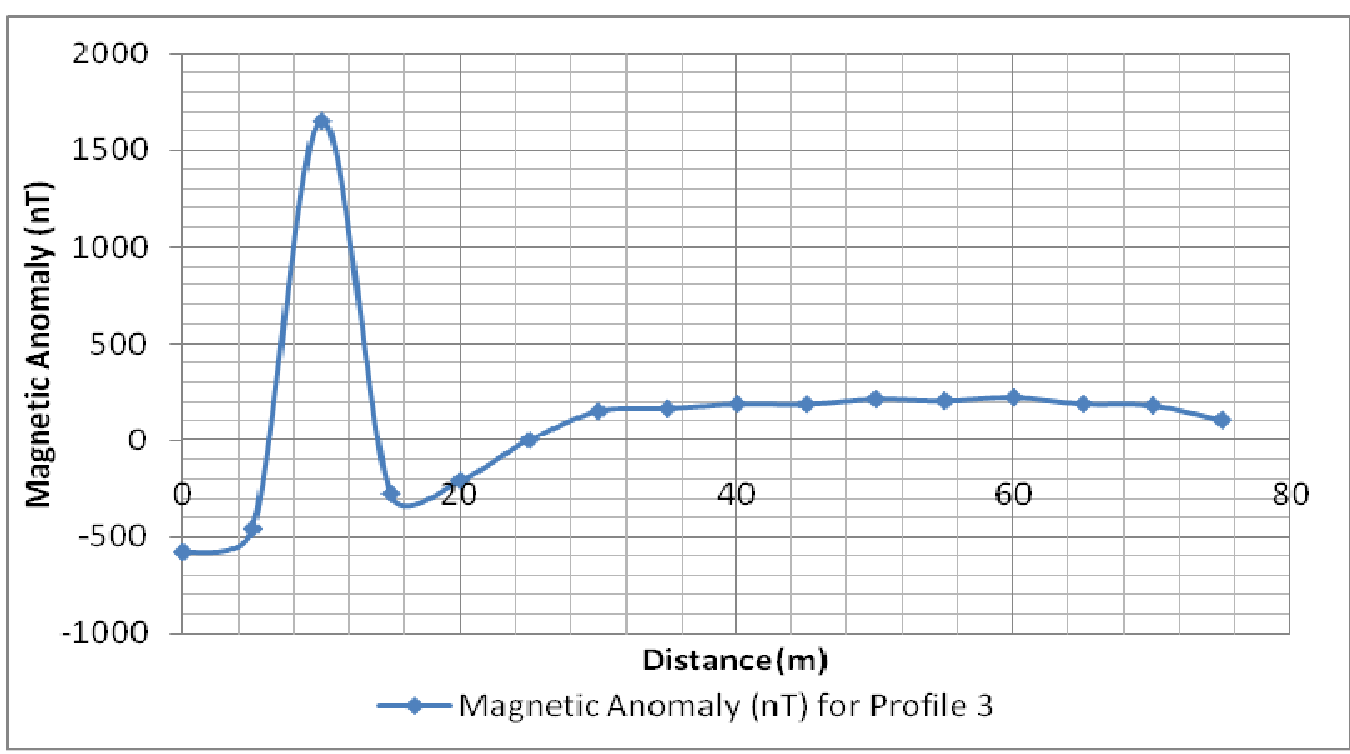

Figure 2c: Magnetic field plot for Profile 3

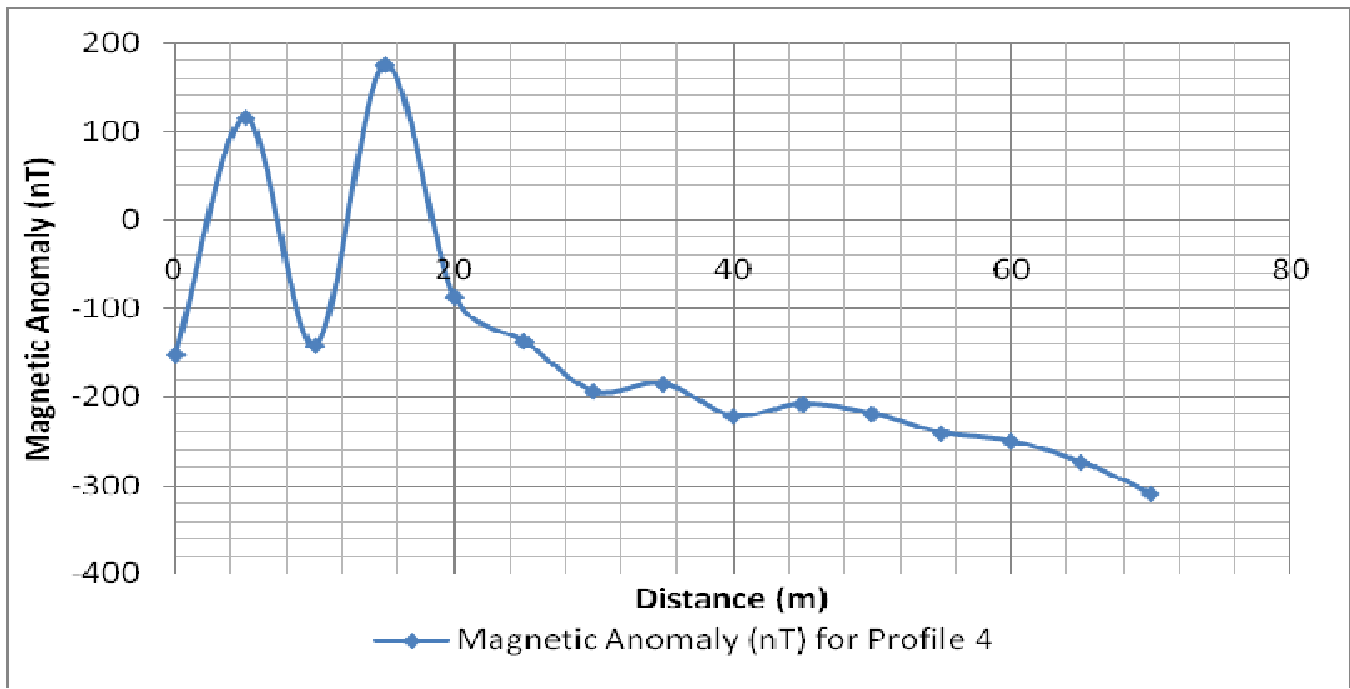

Figure 2d: Magnetic field plot for Profile 4

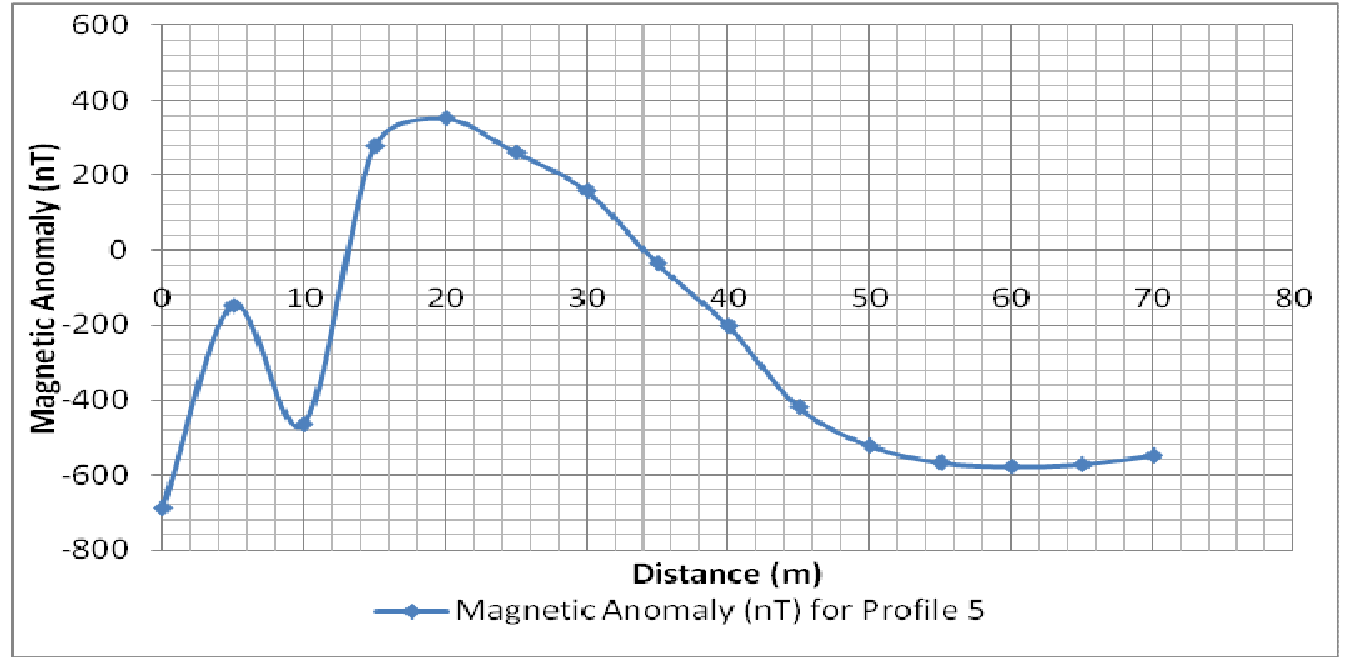

Figure 2e: Magnetic field plot for Profile 5 


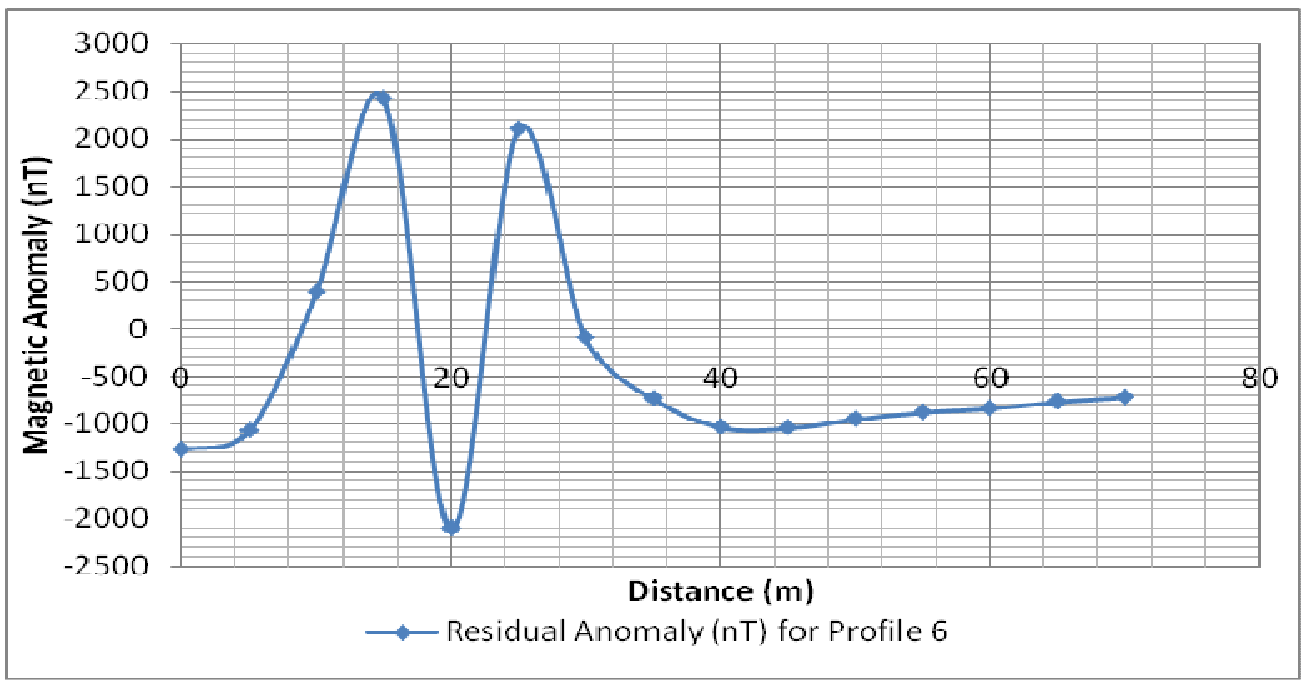

Figure 2f: Magnetic field plot for Profile 6

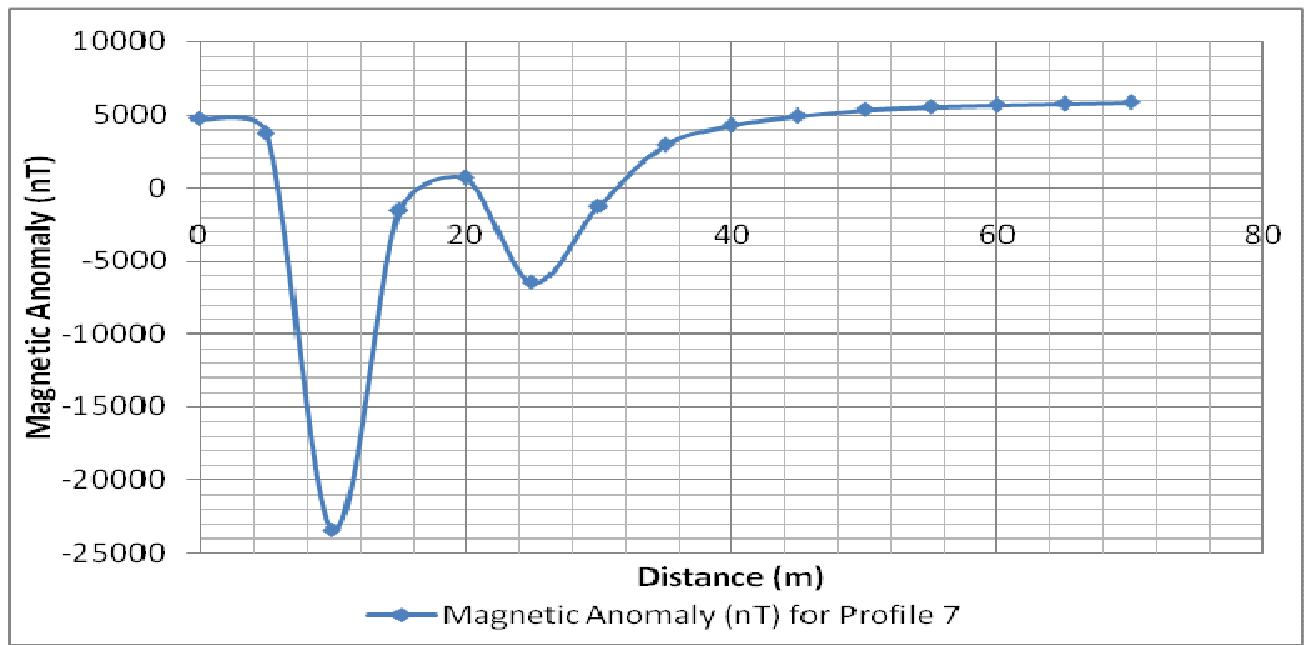

Figure 2g: Magnetic field plot for Profile 7

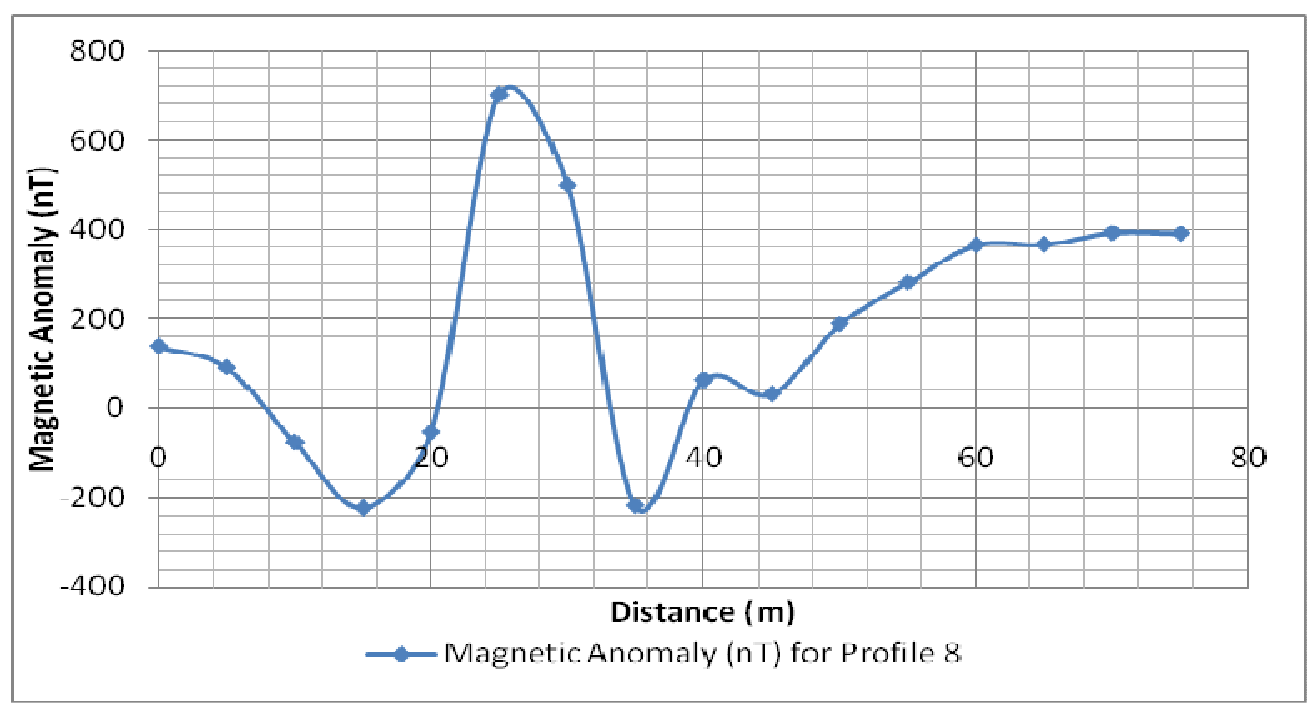

Figure 2h: Magnetic field plot for Profile 8 


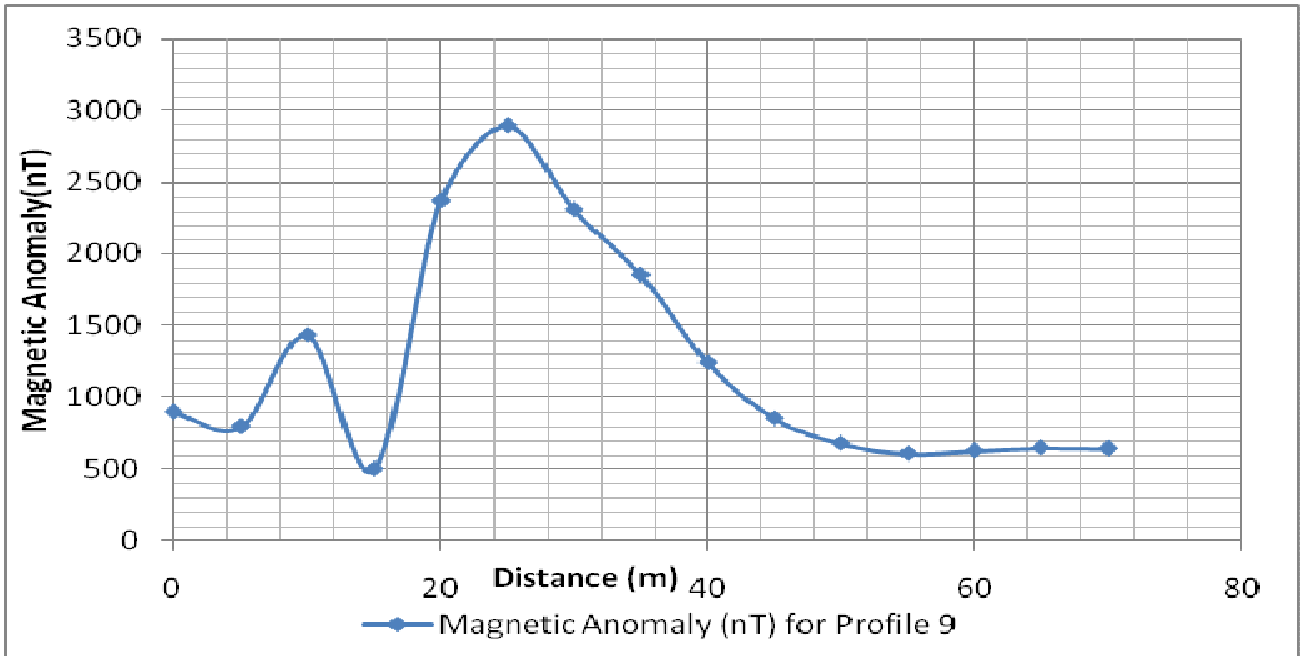

Figure 2i: Magnetic field plot for Profile 9

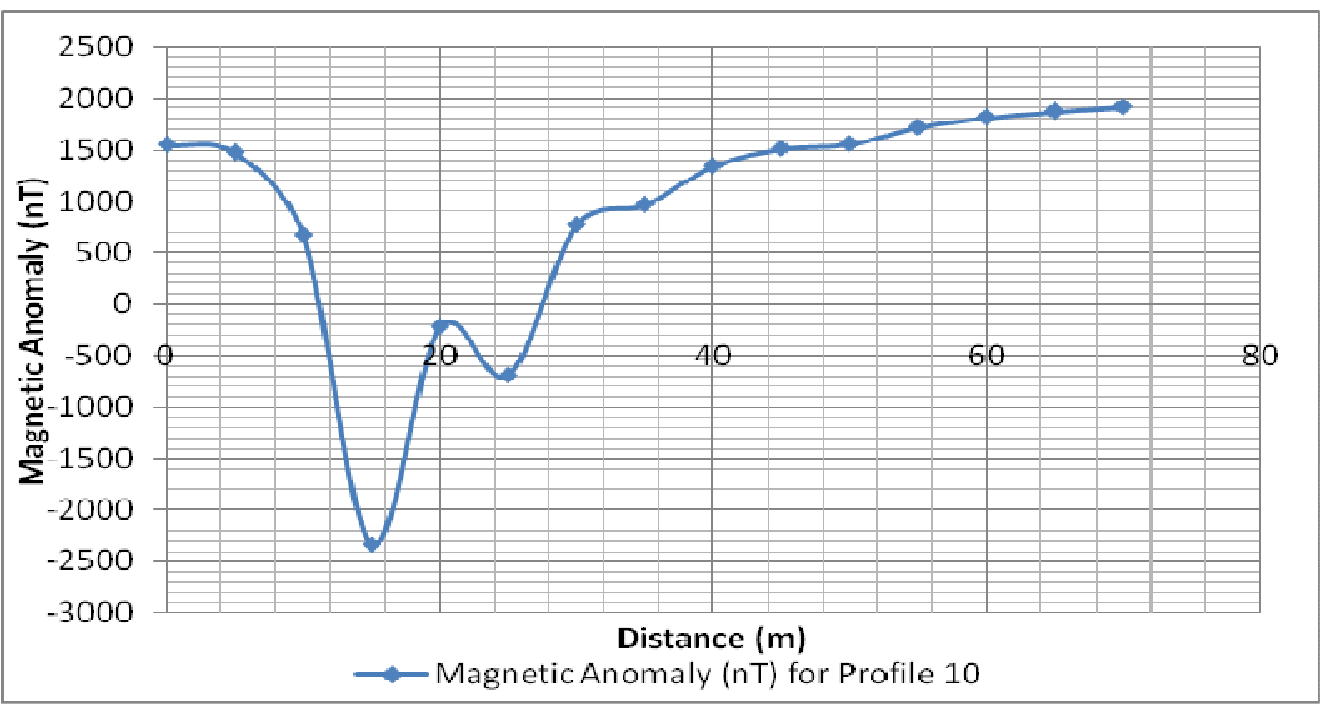

Figure 2j: Magnetic field plot for Profile 10

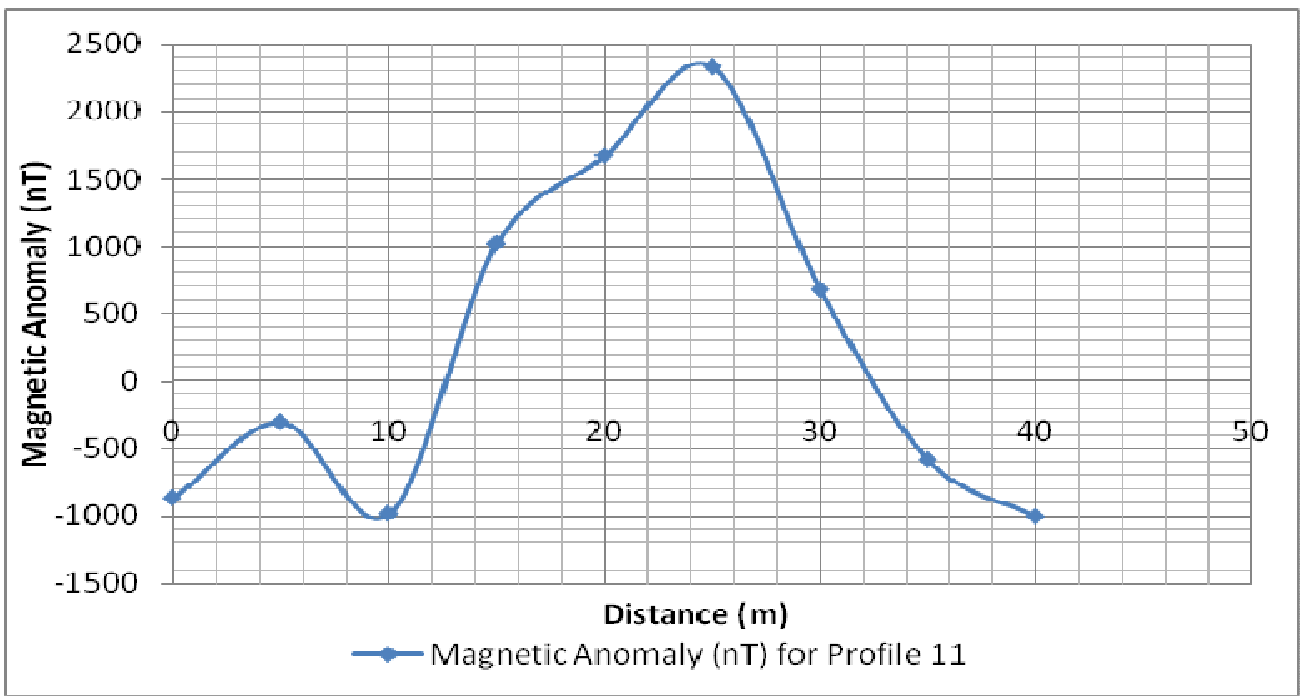

Figure 2k: Magnetic field plot for Profile 11 


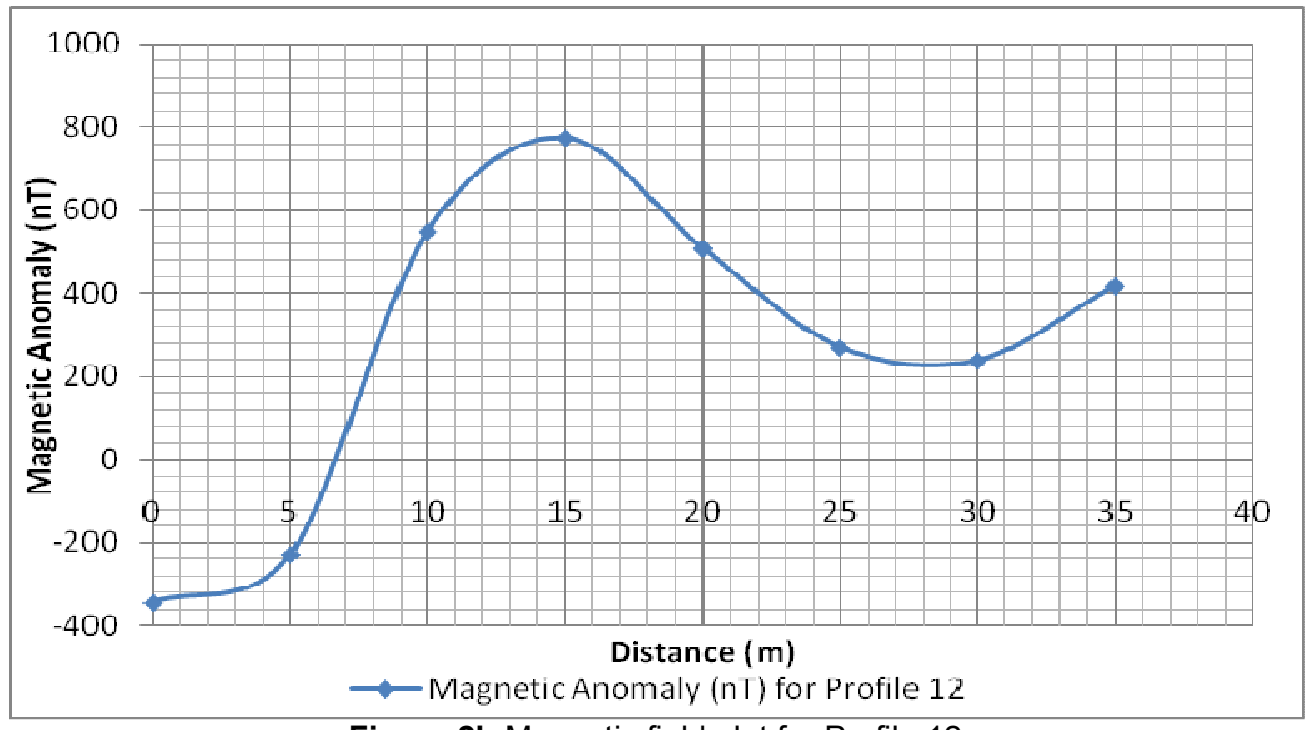

Figure 2I: Magnetic field plot for Profile 12

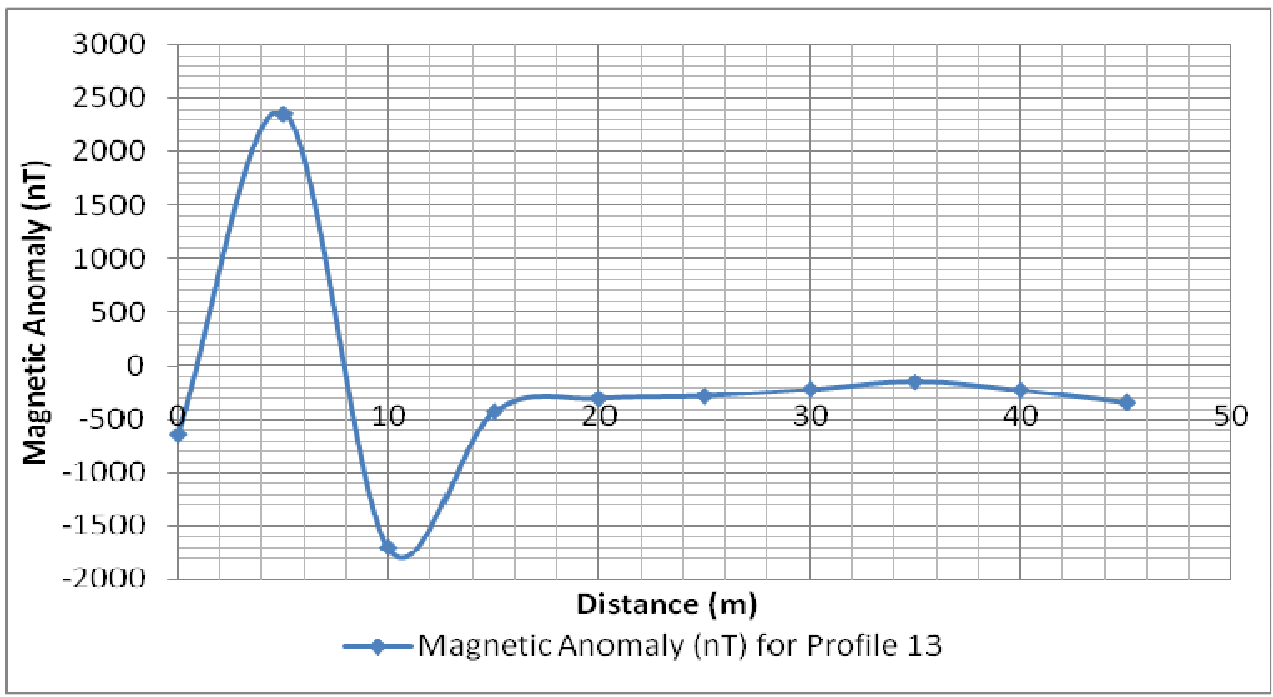

Figure 2m: Magnetic field plot for Profile 13

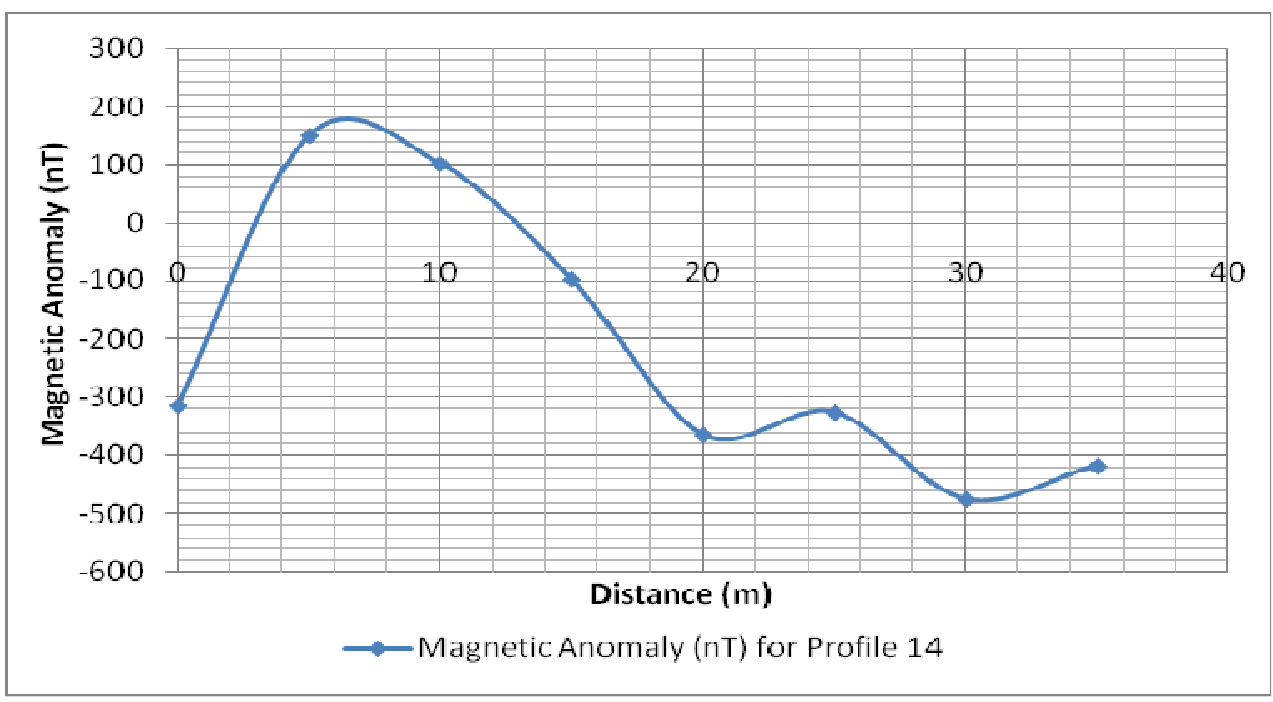

Figure 2n: Magnetic field plot for Profile 14 


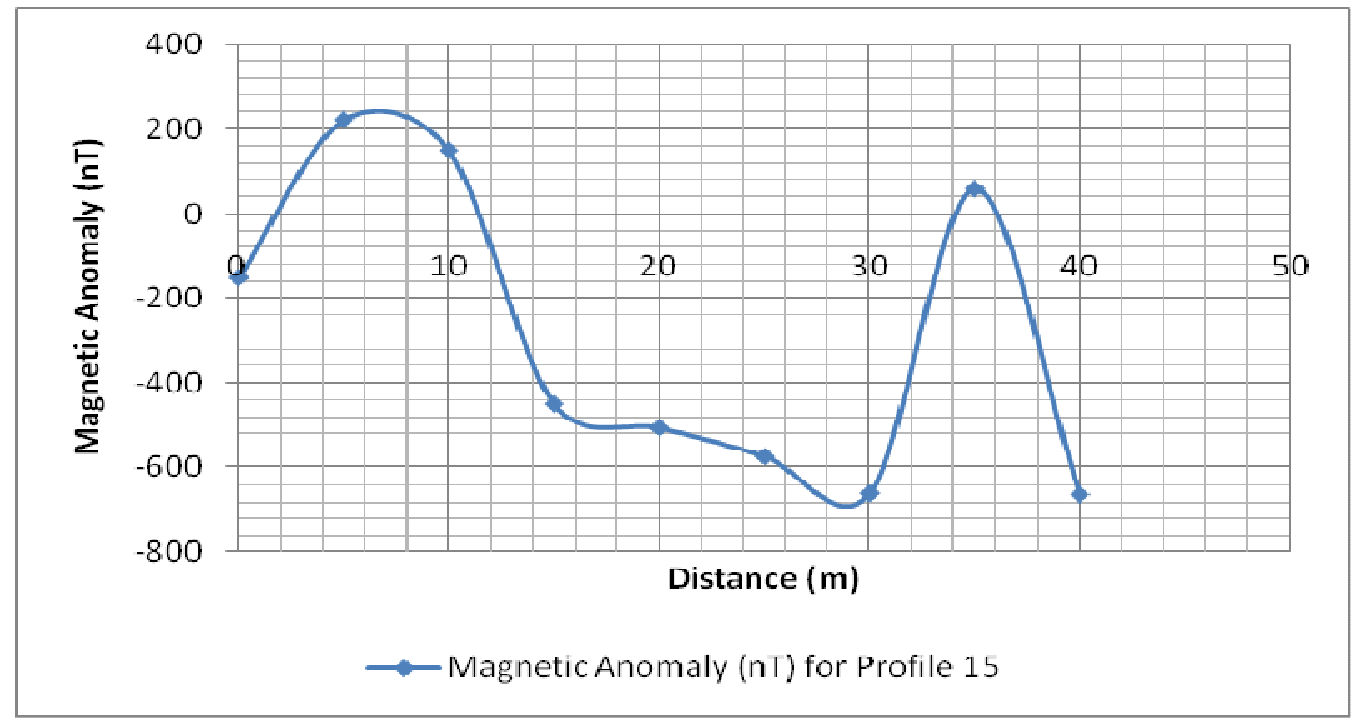

Figure 2o: Magnetic field plot for Profile 15

Table 1.0: Approximate depth to the magnetic sources for the respective profile

\begin{tabular}{|c|c|c|c|c|}
\hline & \multicolumn{3}{|c|}{ ESTIMATED DEPTH (metres) } & \multirow[b]{2}{*}{$\begin{array}{l}\text { AVERAGE } \\
\text { DEPTH }(\mathbf{m})\end{array}$} \\
\hline PROFILE & CONTACT & $\begin{array}{l}\text { THIN } \\
\text { SHEET } \\
\text { (DYKE) }\end{array}$ & $\begin{array}{l}\text { HORIZONTAL } \\
\text { CYLINDER }\end{array}$ & \\
\hline 1 & - & - & - & - \\
\hline 2 & - & - & - & - \\
\hline 3 & 1.62 & 2.80 & 3.65 & 2.69 \\
\hline 4 & 1.28 & 2.20 & 2.87 & 2.12 \\
\hline 5 & 4.56 & 7.89 & 10.29 & 7.58 \\
\hline 6 & 1.62 & 2.80 & 3.65 & 2.69 \\
\hline 7 & 1.57 & 2.71 & 3.54 & 2.61 \\
\hline 8 & 2.45 & 4.23 & 5.52 & 4.07 \\
\hline 9 & 6.01 & 10.4 & 13.57 & 9.99 \\
\hline 10 & 1.39 & 2.40 & 3.13 & 2.31 \\
\hline 11 & 3.61 & 6.25 & 8.15 & 6.00 \\
\hline 12 & 3.61 & 6.25 & 8.15 & 6.00 \\
\hline 13 & 1.30 & 2.25 & 2.94 & 2.16 \\
\hline 14 & 1.93 & 3.34 & 4.35 & 3.21 \\
\hline 15 & 1.97 & 3.42 & 4.46 & 3.28 \\
\hline
\end{tabular}

The individual profile interpretation of the magnetic field plots [figures 2(a-o)] shows variable anomalies which is an indication of susceptibility contrast of the rock types across the study area. This implies that the magnetic source body is not evenly distributed across the study area. Magnetic plots for profiles 1 and 2(figures 2a-b) respectively did not depict any visible form of anomaly in the magnetic field, the magnetic anomaly values was observed decreasing along profile 1 which suggest possible discontinuity in the magnetic basement or faults or fracture zones along this profile line. The magnetic plots were interpreted using the Analytic Signal equations (i, ii, and iii) to determine the estimated depths to the buried magnetic sources (or body) of the survey area as shown in Table 1.0. A visual inspection of the 2D contour map of the study area (Figure 3 ) shows that the contour lines in the southwestern part of the map are widely spaced, indicating that the depth to the magnetic 
source body in this region is relatively high, the magnetic intensities in this region is also high, which indicates that the presence of ferruginous mineral is highly suspected at this part of the study area. Whereas at the northeastern part of the map, the contour lines are closely spaced indicating that the depth to magnetic basement is shallow at this region of the study area. The closely spaced, linear sub-parallel orientation of contours from the southwestern part of the map suggests the possibility of faults or local fractured zones.
On the basis of the variation in magnetic intensity across the study area, there appear a general increase in the intensity from the northeastern part towards the southwestern part of the map which suggests that the iron compound is decreasing from southwestern to north western part. In the same vein, figure 4 shows the 3D surface distribution of the anomaly for the survey area which clearly reveal points and area of magnetic mineral concentration. Magnetic anomaly was visible around the north edge of the map

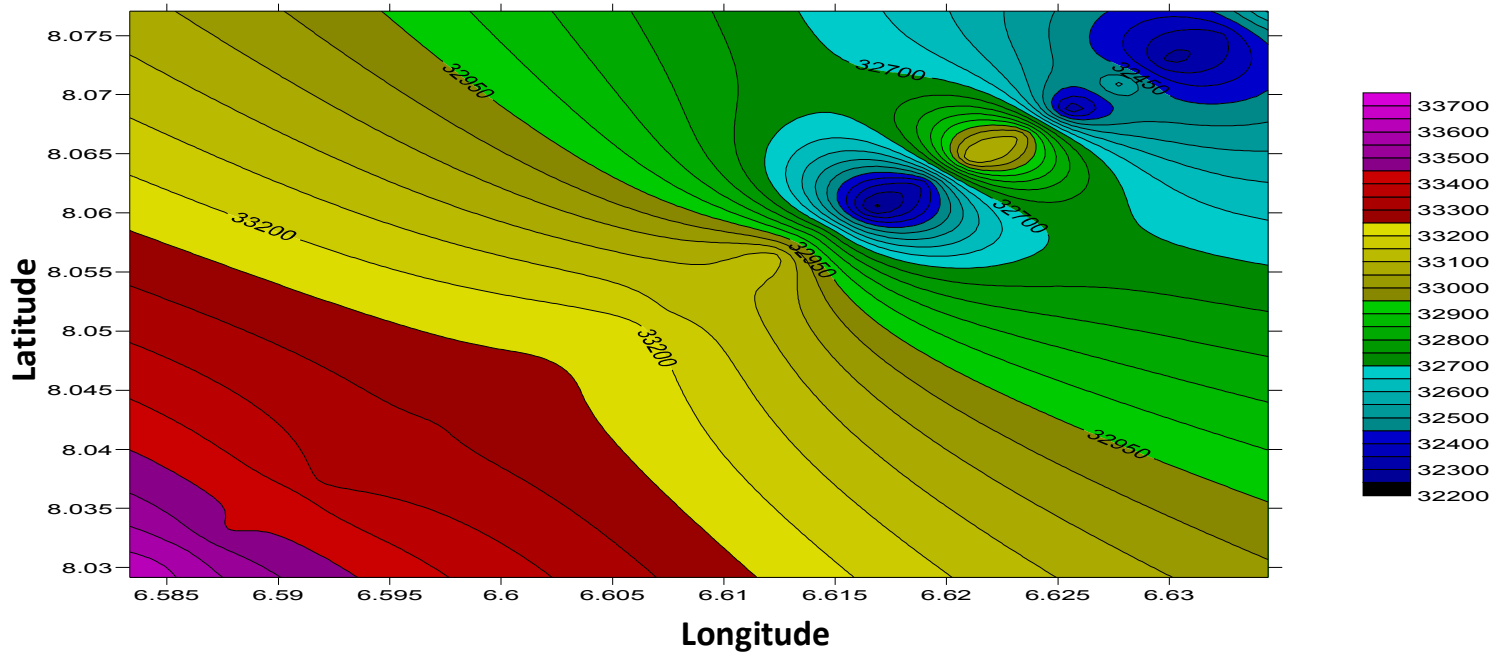

Figure 3: 2D Contour map for the study area

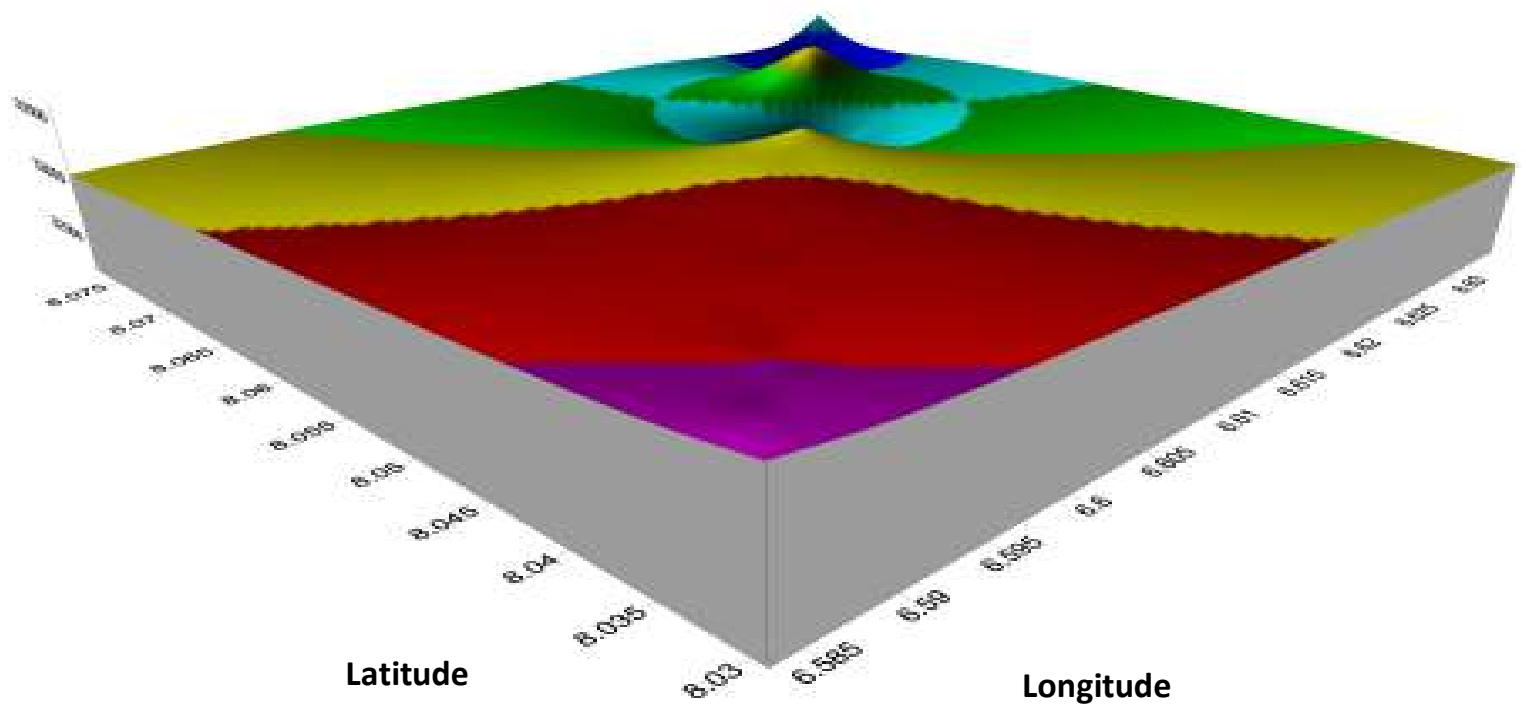

Figure 4: 3D Surface distribution map for the study area

\section{CONCLUSION}

The ground magnetic survey carried out in this research work using high resolution proton precision magnetometer G-856AX has been useful to predict successfully the presence of the iron mineral deposit across the study area. The interpretation of the magnetic data acquired on the study area reveals the varying amplitudes of the anomaly signature, which implies that the magnetic body source is not evenly distributed along the respective profile across the study area. The region of low magnetic intensity on the magnetic profiles 
suggest possible discontinuity or faults or fracture zones whereas the region with high magnetic intensity indicates that the area is underlain with iron deposited mineral. The estimated depths vary between $1.28 \mathrm{~m}$ to $13.57 \mathrm{~m}$ which suggests that the magnetic source body suspected to be magnetic mineral is a near surface feature.

The local geological mapping of the study area revealed that the area is under laid mainly by iron compound and feldspathic sandstone. At the southwestern and northeastern part of the generalized contour map widely spread out indicating that the depth of basement is high in these areas. The variation in magnetic intensity (nT) across the study area, decrease from the southwestern to northeastern part of the map. This implies that the regions of high magnetic anomaly suggested the presence of iron compounds with high susceptibility. The results have demonstrated that careful analysis of magnetic data can give vital information about the zone of magnetic mineralization of the study area.

\section{REFERENCES}

Akintayo, O. O., Omotoso, T. O and Olorunyomi, J. A., 2014. Determination of location and depth of mineral rocks at olode village in Ibadan, Oyo State using geophysical methods. International Journal of Geophysics, volume 2014, article ID 306862

Atchuta Rao D., Ram Babu, H. V and Sanker Narayan, P. V., 1981. Interpretation of Magnetic anomalies due to dykes: The complex gradient method. Geophysics 46, 1572-1578.

Elueze, A. A., 1986. Petrology and Gold mineralization of the Amphibolites belt. llesha area Southwestern Nigeria. Geol. Mijnbouw 65: 189 195.

Folami, S. L., 1998. Aeromagnetic anomalies over the amphibolite complex in Itagumodi area, Southwest Nigeria. Journal of Mining and Geology 27, (1): 31-34.

Joshua, E. O., Adewuyi, S. O and Ojo, O. L., 2013. A study of subsurface geological structure of Sumaje village, Nigeria. Journal of Geology and mining research $5,(9):$ 232-238.

Kayode, J. S., 2009. Vertical components of the ground Magnetic study of ljebu-jesa, Southwestern Nigeria: Global Journal of Engr. \&Tech 2, (3): 475-4 84 .
Kayode, J. S and Adelusi, A. O., 2010. Ground magnetic data interpretation of ljebu-Jesa Area, S/W Nigeria using total component. Research Journal of Applied Sciences, Engineering and Technology 2, (8): 703-709.

Kearey, P and Brooks, M., 1984. An Introduction to Geophysical Exploration: Blackwell Science Ltd, Oxford, 296.

Kearey Philip, Brooks Micheal and Ian Hill. 2002. An Introduction to Geophysical Exploration ( $3^{\text {rd }}$ ed) UK: Blackwell Publishing Company. 155-180.

Lowrie, W., 2007. Fundamentals of Geophysics $2^{\text {nd }}$ ed. Cambridge University Press. Pp 310-324

Macleod, I. N., Jones, K and Dai, T. F., 1993. 3-D Analytic Signal in the interpretation of total magnetic field data at low magnetic latitudes. Exploration Geophysics 24; 679-688.

Nwankwo, L. I., Olasehinde, P. I and Bayewu, O. O., 2006. Depth estimates from a ground magnetic survey across a North-South trending geologic structure in a part of the basement complex terrain of Ilorin, West of central Nigeria. Global J of Pure and Applied Sciences 13, (2): 209-214.

Roest, W. R., Verhoef, J and Pilkington, M., 1992. Magnetic Interpretation using the 3-D analytic signal. Geophysics 57, 116-125.

Telford, W. M., Geldart, L. P and Sheriff, R. E., 2001. Applied Geophysics, $3^{\text {rd }}$ ed, Cambridge University Press, 632-636.

Weymouth, J. W., 1985. Geophysical surveying of archaeological sites surveying: Archaeological Geology. Yale University Press, New Haven London, pp 191-235. 